Quim. Nova, Vol. 35, No. 5, 982-987, 2012

\title{
SPECIFICITY AND SELECTIVITY IMPROVEMENT IN DOPING ANALYSIS USING COMPREHENSIVE TWO- DIMENSIONAL GAS CHROMATOGRAPHY COUPLED WITH TIME-OF-FLIGHT MASS SPECTROMETRY
}

\author{
Samantha S. Barbosa*, Felipe D. Leal, Monica C. Padilha, Raphael S. F. Silva, Henrique Marcelo G. Pereira e Francisco \\ R. Aquino Neto \\ Instituto de Química, Universidade Federal do Rio de Janeiro, 21949-900 Rio de Janeiro - RJ, Brasil \\ Ademário I. da Silva Júnior \\ Instituto Federal de Educação, Ciência e Tecnologia do Rio de Janeiro, campus Rio de Janeiro, 20270-021 Rio de Janeiro - RJ, Brasil
}

Recebido em 5/9/11; aceito em 21/11/11; publicado na web em 31/1/12

\begin{abstract}
Comprehensive two-dimensional gas chromatography coupled with time-of-flight mass spectrometry was used for the identification of forty doping agents. The improvement in the specificity was remarkable, allowing the resolution of analytes that could not be done by one-dimensional chromatographic systems. The sensitivity observed for different classes of prohibited substances was clearly below the value required by the World Anti-Doping Agency. In addition time-of-flight mass spectrometry gives full spectrum for all analytes without any interference from the matrix, resulting in selectivity improvements. These results could support the implementation of an exhaustive monitoring approach for hundreds of doping agents in a single injection.
\end{abstract}

Keywords: comprehensive two-dimensional gas chromatography; doping analysis; time-of-flight.

\section{INTRODUCTION}

Urine is the mandatory biological fluid for the detection of substances with low molecular weight in doping control. Through the last forty years, doping control specialists have implemented very robust methods for doping agents detection. ${ }^{1-3}$ The GC/MS approach was firstly introduced in the 70's, opening the possibility of the implementation of very sensitive methods with a embracing perspective. . $^{4-6}$

Currently, GC/MS after derivatization and selective ion monitoring (SIM) acquisition are necessary to reach suitable detectability for anabolic steroids in routine analysis. ${ }^{7-12}$ This classical procedure also allows the detection of other classes of substances such as narcotics, cannabinoids, $\beta$-agonists, etc. With such a number of exogenous substances and many others from endogenous sources, it is natural to observe co-elution in mono-dimensional chromatographic methods. The World Anti-doping Agency (WADA) regulations for qualitative validation process define specificity as the ability of an assay to detect only the substance of interest, discriminating the analyte from others exogenous substances with closely related structures. On the other hand, selectivity could be understood as the capability of a method in discriminating the analyte from substances naturally present in the matrix (endogenous). ${ }^{13}$

Considering the permanent increase of new substances in WADA's prohibited list, the implementation of more embracing approaches must be evaluated, aiming at reducing the number of methods necessary for screening steps and the consequent simplification of laboratory logistics. . $^{1,214}$

Comprehensive two-dimensional gas chromatography with time of flight mass spectrometry $(\mathrm{GC} \times \mathrm{GC}-\mathrm{TOFMS})$ has demonstrated remarkable results in several fields of analytical chemistry. ${ }^{15-17}$ Nevertheless, in contrast with areas such as environmental ${ }^{18-21}$ and petroleum chemistry, ${ }^{20,22,23}$ few works describe the application of the $\mathrm{GC} \times \mathrm{GC}$-TOFMS system in doping analysis. It was already demonstrated the higher sensitivity of the system with the preservation of the full spectral information relative to the detection of methyltestosterone metabolites, clenbuterol, epimetendiol and 3'OH-stanozolol at $2 \mathrm{ng} /$

\footnotetext{
*e-mail: samanthaquim@gmail.com
}

$\mathrm{mL}{ }^{24,25}$ These anabolic agents have the lowest minimum requirement performance levels (MRPL) according to WADA`s regulations. ${ }^{26}$ The analysis of endogenous sterols and some other anabolic agents were also presented by the GC $\times$ GC. ${ }^{27,28}$ In addition, the WADA's qualitative criteria of retention time and ion ratio in the $\mathrm{GC} \times \mathrm{GC}$ system were deep evaluated. ${ }^{29}$

The quadrupole analyzer (qMS) has been an important tool in doping control and toxicological laboratories allowing very sensitive analysis. Nevertheless, the time of flight mass spectrometer (TOFMS), a nonscanning MS instrument, is the ideal MS detector for comprehensive two-dimensional gas chromatography due to its high acquisition rate (up to $500 \mathrm{spectra} / \mathrm{s}$ ). Another advantage of TOFMS over scanning MS instruments, as qMS, is the absence of lost ions and the acquisition of all ions at the same point of a chromatogram, which produces no skewed spectra even in fast GC..$^{30,31}$ This leads to the achievement of non-distorted mass spectra throughout the whole chromatographic peak, which allows spectral deconvolution by the statistical analysis of fragmentation patterns and the identification of co-eluting compounds, if they have different mass spectrum. The combination between higher chromatographic resolution and spectral deconvolution makes GC $\times$ GC-TOFMS ideal for the analysis of complex samples like urine.

The synergistic effect of higher chromatographic resolution (from $\mathrm{GC} \times \mathrm{GC}$ ), spectral deconvolution and acquisition of full spectra (from TOFMS) allows the GC $\times$ GC-TOFMS system to become a comprehensive method in doping control, increasing drastically the number of substances monitored of a single analytical run.

However, more work involving the application of this multi-dimensional approach is necessary before the effective implementation of this strategy as an ultimate tool in doping analysis. This is particularly relevant if the detection of non-target analytes is desired..$^{9,32-34}$ The presence of this new chemical entities could have obvious impact in the specificity of methods already employed. Besides, the revaluation of samples already analyzed could follow any suspicious or proved novel malpractices by athletes, since the full mass spectra of the whole separation in urine samples would always be available.

Considering the exposed, the aim of the present work was to evaluate the impact of the two-dimensional chromatographic approach 
in the specificity, characterization and identification of several doping agents from different pharmacological classes in a single analytical run using the $\mathrm{GC} \times \mathrm{GC}$-TOFMS approach. In addition, the impact of the improvement in resolution and software spectral deconvolution using the $\mathrm{GC} \times \mathrm{GC}$-TOFMS system will be demonstrated by using the metabolite of the doping agent $\Delta^{9}$-tetrahydrocannabinol (THC) as an example.

\section{EXPERIMENTAL}

\section{Quality assurance}

All analytical and managerial procedures related to sample preparation were accredited at the ISO/IEC 17025 standard, by the Brazilian National Metrological Institute (INMETRO) ${ }^{35}$ jointly with the WADA International Standard for Laboratories (ISL). ${ }^{13}$

\section{Reagents and chemicals}

3'-Hydroxystanozolol (stanozolol metabolite), $5 \alpha$-estran- $3 \alpha$ ol-17-one (norandrosterone) and $5 \beta$-estran- $3 \alpha$-ol-17-one (noretiocholanolone) - which are nandrolone metabolites $-17 \alpha$-methyl-5 $\alpha$-androstane- $3 \alpha, 17 \beta$-diol (methyltestosterone metabolite), $5 \alpha$-epoxy-1-methylen-5 $\alpha$-androstan-3 $\alpha$-ol-17-one (metenolone metabolite), $2 \alpha$-methyl-5 $\alpha$-androstan-3 $\alpha$-ol-17-one (drostanolone metabolite), $17 \alpha$-hydroxy-17 $\alpha$-methyl-2-oxa- $5 \alpha$-androstan-3-one (17-epioxandrolone), 4-chloroandrost-4-en-3 $\alpha$-ol-17-one (clostebol metabolite), 4-hydroxyandrost-4-ene-3,17-dione (formestane), $9 \alpha$ fluoro-17 $\alpha$-methylandrost-4-ene-3 $\alpha, 6 \beta, 11 \beta, 17 \beta$-tetrol (fluoxymesterone metabolite), 16z-hydroxyfurazabol (furazabol metabolite), $[5 \alpha, 7 \alpha(S)]-17-($ Cyclopropylmethyl)- $\alpha$-(1,1-dimethylethyl)-4,5epoxy-18,19-dihydro-3-hydroxy-6-methoxy- $\alpha$-methyl-6,14-ethenomorphinan-7-methanol (buprenorphine) and $7 \alpha-17 \alpha$-dimethyl-5 $\beta$-androstane- $3 \alpha, 17 \beta$-diol (bolasterone metabolite), hydroxybromantane (bromanthane metabolite) were a kind gift from Dr. W. Schänzer and H. Geyer from the Institute of Biochemistry, Germany Sports University, Cologne, Germany. $17 \beta$-Methyl-5 $\beta$-androst-1-en-3 $\alpha-17 \alpha$ diol, epimetendiol (EMD), was bought from AGAL (Canberra, Australia). 5 $\beta$-Androst-1-en-17 $\beta$-ol-3-one (boldenone metabolite) was bought from Steraloids (Newport, USA). Methyltestosterone used as an internal standard was bought from Aldrich (Milwaukee, WI, USA). N,N-Diethyl-4-hydroxy-3-methoxybenzamide (ethamivan), 2-amino-5-phenyl-1,3-oxazol-4-one (pemoline), 4-[2-(tertbutylamino)-1-hydroxyethyl]-2-(hydroxymethyl)phenol (salbutamol), 1-(4-amino-3,5-dichlorophenyl)-2-(tert-butylamino)ethanol (clenbuterol), 1-(4-amino-3,5-dibromophenyl)-2-(tert-butylamino) ethanol (brombuterol), 4-(dipropylsulfamoyl)benzoic acid (probenecid), androsta-1,4-diene-6-methylene-3,17-dione (exemestane), $1 \alpha$-methyl-5 $\alpha$-androstan-3 $\alpha$-ol-17-one (mesterolone metabolite) and $\Delta^{9}$-THC-11-oic acid (THC metabolite - carboxy-THC) were bought from Sigma (St. Louis, MO, USA). 6-(Dimethylamino)-4,4diphenylheptan-3-one (methadone) and 8-hydroxy-5-[1-hydroxy2-(propan-2-ylamino)butyl]-1H-quinolin-2-one (procaterol) and 3,14-dihydroxy-17-methylmorphinan-6-one (oxymorphone) were a kind gift from Dr. Jordi Segura from the IMIM (Hospital Del Mar Research Institute) Barcelona, Spain. $5 \alpha$-Estran-3 $\alpha$-ol-17-one (19-norandrosterone, nandrolone metabolite) and $18 \beta, 17 \alpha$-diethyl-5 $\beta$-estrane-3 $\alpha, 17 \beta$-diol (norbolethone metabolite), 2-[4-[(Z)-1,2diphenylbut-1-enyl]phenoxy]-N,N-dimethylethanamine (tamoxifen) and $7 \beta, 17 \alpha$-dimethyl-5 $\beta$-androstane- $3 \alpha, 17 \beta$-diol (calusterone metabolite) were a kind gift from Dr. Catrin Goebel from the Australian Sports Drug Testing Laboratory (ASDTL) Sydney, Australia. 4,5- $\alpha$-Epoxy-3-hydroxy-17-methylmorphinan-6-one (hydromorphone), (5R,9R,13S,14S)-4,5 -epoxy-14-hydroxy-3methoxy-17-methylmorphinan-6-one (oxycodone) and $(5 \alpha, 6 \alpha)$ 7,8- dehydro - 4,5-epoxy-17-methylmorphinan-3,6-diol (morphine) and $17 \alpha$-ethyl-5 $\beta$-estrane- $3 \alpha, 17 \beta$-diol (norethandrolone metabolite) and $17 \alpha$-methylandrost-4-ene-4, 17 $\beta$-diol-3-one (oxymesterone) were bought from Radian (Lafayette, IN, USA). 2-[4-[2-(3,5-Dimethylanilino)-2-oxoethyl]phenoxy]-2-methylpropanoic acid (RSR 13) was bought from Hovione Farmaciência (Loures, Portugal). 3 $\alpha$-Hydroxytibolone (tibolone metabolite) was bought from LIBBS Pharmaceutical (Embu, Brazil). 17 $\alpha$-Methyl2-oxa- $5 \alpha$-androstan-17 $\beta$-ol-3-one (oxandrolone), 6-phenylpteridine2,4,7-triamine (triamterene), $17 \alpha$-Hydroxypregn-4-en-20-yn-3-one (danazol metabolite), $\alpha$-zeranol and $\beta$-zeranol (zeranol metabolites), clenbuterol, 1-[4-amino-3-chloro-5-(trifluoromethyl)phenyl]-2-(tertbutylamino)ethanol (mabuterol) were bought from Sigma (Abbott, São Paulo, Brazil). All reagents were analytical grade. N-Methyl$\mathrm{N}$-(trimethylsilyl)trifluoroacetamide (MSTFA) was purchased from Chem Fabrik (Waldstetten, Germany). $\mathrm{NH}_{4} \mathrm{I}$ and 2-mercaptoethanol from Sigma (St. Louis, MO, USA). Tert-butylmethylether (TBME) and methanol from Tedia (Fairfield, USA).

\section{Sample pre-treatment and purification}

Blank urine samples that were negative for all substances foreseen in WADA's prohibited list were spiked with 40 known doping agents/ metabolites. The samples were processed for screening analysis of anabolic substances as described in a previous work. ${ }^{36}$ Briefly, 2 $\mathrm{mL}$ of urine were spiked with $1000 \mathrm{ng}$ methyltestosterone (internal standard - ISTD). $750 \mu \mathrm{L}$ of phosphate buffer (pH 7) and $50 \mu \mathrm{L}$ of $\beta$-glicuronidase from $E$. coli were added to hydrolysis purposes. After incubation $\left(1\right.$ hour at $\left.50{ }^{\circ} \mathrm{C}\right), 500 \mu \mathrm{L}$ of carbonate buffer $(\mathrm{pH}$ 9) and $5 \mathrm{~mL}$ of TBME were added. The sample was shaken and then centrifuged at $3000 \mathrm{rpm}$. The organic phase was dried at $40{ }^{\circ} \mathrm{C}$ under a stream of nitrogen gas. The residue was kept under vacuum in a dessicator for $30 \mathrm{~min}$ and then it was dissolved in $100 \mu \mathrm{L}$ of MSTFA-NH $\mathrm{N}_{4}$-2-mercaptoethanol (1000:2:6, v/w/v) and heated at $60{ }^{\circ} \mathrm{C}(20 \mathrm{~min})$.

\section{Instrumentation and chromatographic conditions}

The GC $\times$ GC-TOFMS system used was a Pegasus 4D (Leco, St. Joseph, MI, USA) composed of an Agilent 6890 GC (Palo Alto, CA, USA) equipped with a secondary oven and a non-moving quad-jet dual-stage modulator. ChromaTOF ${ }^{\circledR}$ software version 2.32 (LECO Corp., St. Josephs, MI) was used for data acquisition. The first column (1D) was an Ultra-1 (Agilent Technologies, Inc., St. Clara, CA, USA), $100 \%$ polymethylsiloxane, $17 \mathrm{~m}, 0.2 \mathrm{~mm}$ I.D., $0.11 \mu \mathrm{m}$ film thickness and the second column (2D) was an OV-1701 (MEGA, Milan, Italy), poly-14\%-cyanopropylphenyl-86\%-dimethylsiloxane, 1 $\mathrm{m}, 0.1 \mathrm{~mm}$ I.D., $0.1 \mu \mathrm{m}$ film thickness. The $2 \mathrm{D}$ column was connected to the TOFMS by means of a $0.5 \mathrm{~m} \times 0.25 \mathrm{~mm}$ i.d. empty deactivated fused silica capillary, which was connected via SGE mini-unions and SiltiteTM metal ferrules 0.1-0.25 mm i.d. (Ringwood, VIC, Australia). The injection mode of $3 \mu \mathrm{L}$ was split $1: 10$ at $280{ }^{\circ} \mathrm{C}$. The gas flow rate was $1.2 \mathrm{~mL} / \mathrm{min}$ using helium as carrier gas. Primary oven temperature program was $140^{\circ} \mathrm{C}$ for $1 \mathrm{~min}$, ramped at $40^{\circ} \mathrm{C} / \mathrm{min}$ to 180 ${ }^{\circ} \mathrm{C}$, then at $3{ }^{\circ} \mathrm{C} / \min$ to $280{ }^{\circ} \mathrm{C}$, then ramped at $40{ }^{\circ} \mathrm{C} / \min$ to $330{ }^{\circ} \mathrm{C}$. The secondary oven was $20^{\circ} \mathrm{C}$ higher than the first oven, likewise programmed to stop at $330{ }^{\circ} \mathrm{C}$. The modulation period was $6 \mathrm{~s}$ with 0.8 s hot pulse duration and $a 5^{\circ} \mathrm{C}$ modulator temperature offset versus the primary oven temperature. The MS transfer line was held at 280 ${ }^{\circ} \mathrm{C}$. The TOFMS was operated in the electron ionization mode with collected mass range of $50-750 \mathrm{~m} / \mathrm{z}$. Ion source temperature was 230 
${ }^{\circ} \mathrm{C}$, the detector was operated at $2000 \mathrm{~V}$, the applied electron energy was $70 \mathrm{eV}$ and the acquisition rate was $100 \mathrm{spectra} / \mathrm{s}$.

\section{RESULTS AND DISCUSSION}

To achieve the goal of the project, the sample preparation should be carefully chosen to guarantee the recovery of the largest possible number of doping agents from the matrix. The sample preparation procedure proposed ${ }^{36}$ includes a highly non-specific liquid-liquid extraction step with methyltertbutylether in alkaline medium $(\mathrm{pH}$ 9). The method allows the extraction of several doping agents from urine in high yields and applying a single and fast procedure. This is followed by a sylilation, resulting in TMS-ethers. The major testosterone precursors/metabolites and testosterone itself can be efficiently monitored, allowing the quantitative approach necessary for the evaluation of steroid profile. The high degree of coverage in extraction can be attested by the large number of prohibited analytes - steroids or not - which are monitored in routine through this sample preparation. Indeed, the limiting step of this approach is not the extraction, but the derivatization. ${ }^{34}$ For example, 4,9,11 ene-3-keto steroids usually present low detectability. ${ }^{33}$ Nevertheless, exogenous steroids and other doping agents can be extracted from the matrix and transformed in O-TMS or N-TMS derivatives.

Using a similar sample preparation approach, an embracing method was proposed for the detection of different classes of doping agents in a single analytical run using a GC/MS (Q). ${ }^{12}$ The approach was based in the new electronics of the MS quadrupole allowing the acquisition in full scan and SIM, simultaneously. However, despite of the good performance reported and the continuous improvement in the speed of the quadrupole systems, it will hardly defeat the high performance of TOFMS systems in spectra acquisition ratio. This could be more critical when ultimate chromatography resolution is achieved.

The task to find each analyte in the GC $\times$ GC chromatogram for the first time during the optimization process could be tedious and laborious. This step was significantly speeded up using the mathematic model previously reported. ${ }^{24}$ The model is based on the relationship between the retention time observed for a reduced number of analytes in the $\mathrm{D}^{1}$-GC/MS and the same parameter observed in the $\mathrm{GC} \times \mathrm{GC}$ system. The linear regression study allows the interpolation of the retention times of other analytes obtained in both techniques, since the regression curve obtained after the identification of a limited number of substances in the GC $\times$ GC chromatogram smoothes the identification of subsequent analytes.

Table 1 presents the results of identification process in the $\mathrm{GC} \times$ $\mathrm{GC}$ system. Forty doping agents from eight different pharmacological classes prohibited by WADA were identified in the urine sample. The analytes were spiked in urine at $100 \mathrm{ng} / \mathrm{mL}$. This value is the MRPL established by WADA for $\beta$-agonists and it is below the MRPL for several drug classes included in the study as narcotics $(200 \mathrm{ng} / \mathrm{mL})$, $\beta$-blockers $(500 \mathrm{ng} / \mathrm{mL})$, diuretics $(250 \mathrm{ng} / \mathrm{mL})$ and stimulants $(500$ $\mathrm{ng} / \mathrm{mL}$ ). The Figure $1 \mathrm{~S}$ (supplementary material) shows the separation power of GC $\times$ GC-TOFMS even with co-elutions compounds could be separated as 4 and 5, 7 and 8 in spiked sample (a) and in blank urine sample (b). A lot of class of compounds such as $\beta 2$-agonist (1), narcotics $(2,3,5)$, stimulant $(6)$, anabolic androgenic steroids $(4,7$, 8 ) and selective estrogen receptor modulator (9) could be identified as a structured chromatogram.

Table 1. Doping agents from different pharmacological classes identified in the GC GC-TOFMS system in a single analytical run

\begin{tabular}{|c|c|c|c|}
\hline Name & Derivative & $\mathrm{t}_{\mathrm{R} 1} \times \mathrm{t}_{\mathrm{R} 2}(\mathrm{~s})$ & Diagnostic ions $(\mathrm{m} / \mathrm{z})$ \\
\hline Mabuterol & N,O-TMS & $300 \times 1.690$ & $86,369,371$ \\
\hline Etamivan & O-TMS & $336 \times 2.950$ & $223,294,295$ \\
\hline Pemoline & N-TMS & $366 \times 2.130$ & $163,178,392$ \\
\hline Salbutamol & O-TMS & $384 \times 1.900$ & $86,369,440$ \\
\hline Clenbuterol & N,O-TMS & $438 \times 2.300$ & $86,335,337$ \\
\hline Metadone & N-TMS & $558 \times 2.800$ & $72,296,381$ \\
\hline Brombuterol & N,O-TMS & $588 \times 2.860$ & $335,351,407$ \\
\hline Probenecide & O-TMS & $588 \times 4.670$ & $193,328,342$ \\
\hline Procaterol & N,O,O'-TMS & $702 \times 2.740$ & $100,407,408$ \\
\hline 19-Norandrosterone & bis O-TMS & $786 \times 2.980$ & $315,405,420$ \\
\hline 19-Noretiocolanolone & bis O-TMS & $852 \times 3.100$ & $405,420,422$ \\
\hline Hydromorphone & O-TMS & $840 \times 3.900$ & $234,414,429$ \\
\hline Oxycodone & O-TMS & $852 \times 4.030$ & $312,444,459$ \\
\hline Morphine & bis O-TMS & $858 \times 4.090$ & $236,414,429$ \\
\hline $2 \alpha$-methyl-5 $\alpha$-androstan-3 $\alpha$-ol-17-one (Drostanolone metabolite) & bis O-TMS & $930 \times 3.110$ & $169,433,448$ \\
\hline Oxymorphone & tris O,O',O"-TMS & $930 \times 3.610$ & $355,502,517$ \\
\hline 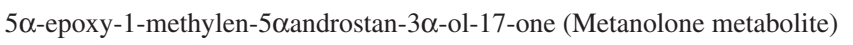 & bis O-TMS & $966 \times 3.320$ & $431,432,446$ \\
\hline Hydroxybromantane (Bromantane metabolite) & O-TMS & $972 \times 5.250$ & $91,393,395$ \\
\hline RSR 13 & N-TMS & $972 \times 4.000$ & $220,326,485$ \\
\hline $17 \alpha$-methyl-5 $\alpha$-androstane- $3 \alpha, 17 \beta$-diol (Methyltestosterone metabolite) & bis O-TMS & $1008 \times 3.290$ & 143,255 \\
\hline Exemestane & O-TMS & $1038 \times 6.35$ & $221,353,368$ \\
\hline $7 \beta, 17 \alpha$-dimethyl-5 $\beta$-androstane-3 $\alpha, 17 \beta$-diol (Calusterone metabolite) & bis O-TMS & $1068 \times 3.320$ & $143,374,449$ \\
\hline $7 \alpha$-17 $\alpha$-dimethyl- $5 \beta$-androstane- $3 \alpha, 17 \beta$-diol (Bolasterone metabolite) & bis O-TMS & $1098 \times 3.420$ & $143,284,374$ \\
\hline
\end{tabular}


Table 1. continuation

\begin{tabular}{|c|c|c|c|}
\hline Name & Derivative & $\mathrm{t}_{\mathrm{R} 1} \times \mathrm{t}_{\mathrm{R} 2}(\mathrm{~s})$ & Diagnostic ions $(\mathrm{m} / \mathrm{z})$ \\
\hline $17 \alpha$-ethyl- $5 \beta$-estrane- $3 \alpha, 17 \beta$-diol (Noretandrolone Metabolite) & bis O-TMS & $1104 \times 3.450$ & $157,331,421$ \\
\hline 4-chloroandrost-4-en-3 $\alpha$-ol-17-one (Clostebol metabolite) & bis O-TMS & $1104 \times 3.710$ & $451,466,468$ \\
\hline Exemestane & bis O-TMS & $1128 \times 4.040$ & $321,411,426$ \\
\hline Methyltestosterone (Internal Standard) & bis O-TMS & $1176 \times 3.850$ & 446 \\
\hline Carboxi-THC & bis O-TMS & $1188 \times 3.980$ & $371,473,488$ \\
\hline Etisterone & bis O-TMS & $1206 \times 3.730$ & 301,456 \\
\hline Oxandrolone & O-TMS & $1212 \times 1.360$ & $143,308,363$ \\
\hline $18 \beta, 17 \alpha$-diethyl-5 $\beta$-estrane- $3 \alpha, 17 \beta$ diol (Norbolethone metabolite) & bis O-TMS & $1218 \times 3.540$ & $157,345,435$ \\
\hline Trianterene & tris N-TMS & $1266 \times 4.440$ & 454,469 \\
\hline$\alpha$-Zeranol & tris O-TMS & $1284 \times 4.000$ & $433,523,538$ \\
\hline $9 \alpha$-fluoro-17 $\alpha$-methylandrost-4-ene- $3 \alpha, 6 \beta, 11 \beta, 17 \beta$-tetrol (Fluoximesterona metabolite) & tetrakis O-TMS & $1302 \times 3.100$ & $143,552,642$ \\
\hline Oxymesterone & tris O-TMS & $1416 \times 3.680$ & $389,519,534$ \\
\hline Tamoxifen & O-TMS & $1506 \times 4.670$ & $58,72,489$ \\
\hline 16z-hydroxyfurazabol (Furazabol metabolite) & bis O-TMS & $1662 \times 6.440$ & $218,231,490$ \\
\hline 3' hydroxystanozolol & tris $\mathrm{N}, \mathrm{O}, \mathrm{O}^{\prime}-\mathrm{TMS}$ & $1734 \times 3.990$ & $254,545,560$ \\
\hline Buprenorphine & bis O-TMS & $1992 \times 4.590$ & $173,506,554$ \\
\hline
\end{tabular}

As expected, through the evaluation of the signal to noise ratio obtained for the analytes spiked at $100 \mathrm{ng} / \mathrm{mL}$, the sensitivity of the $\mathrm{GC} \times \mathrm{GC}$ system for these classes of drugs is more than suitable. The raw data for the limit of detection can be determined after the validation process. Since it is not the aim of this work, the sensitivity and other validation parameters will be not detailed here. Nevertheless, considering the anabolic agents, the concentration level spiked is ten times the MRPL stipulated by WADA. This concentration level was intentionally chosen to highlight the improvement of resolution, since the sensitivity of the GC $\times$ GC-TOFMS system was already demonstrated for anabolic agents at their MRPL. ${ }^{24}$

In routine work, the co-elutions observed and the expected low concentrations for anabolic agents justify the use of SIM acquisition modes in routine analysis with quadrupole mass spectrometer. Losses in mass spectrum information are a natural consequence. According to the technical document for "Identification criteria for qualitative assays incorporating column chromatography and mass spectrometry" ${ }^{37}$ from WADA, before an adverse analytical finding being declared by the laboratory "for GC/MS, in order to ensure that a large amount of a co-eluting substance could not give rise to the observed diagnostic ions, a full scan spectrum shall be acquired at the retention time of the peak(s) of interest". The analytical relevance of this document regarding the qualitative approach was already discussed by our group elsewhere. ${ }^{38}$ The purpose in obtaining the full scan spectrum is to verify and document the absence of spectral interference from other substances (endogenous or exogenous) possibly present in the sample. This new paradigm in specificity could have a huge impact in the analytical strategy since the potential of co-elution in a typical urine sample is extremely large. Depending on the doping agent, modifications in sample preparation (more time consuming) and alternative chromatography programming could be necessary. Obviously, this improvement in the specificity will increase the logistic and manpower needed. A system with high chromatographic resolution power (lack of interference) and full spectra information (specificity) is highly welcomed.

Using the GC $\times$ GC-TOFMS system, the full spectra were obtained for all analytes. Observing the experimental conditions described, just two analytes (exemestane and furazabol metabolite) presented wrap-around, the phenomenon in which second-dimension peaks leave the second column in a modulation later than the one in which they entered the second column. ${ }^{39}$ The classic wrap around profile for exemestane can be observed in Figure 1. Despite the wrap-around, a correct identification of analytes occurred in both cases without harming qualitative analysis.

$$
\text { Masses } 221353368
$$

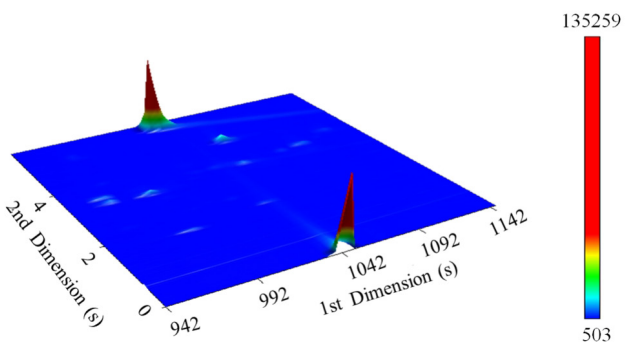

Figure 1. GC $\times$ GC chromatogram for exemestane mono-OTMS, wrap around profile

In GC/MS (one-dimensional chromatography) several co-elutions between exogenous doping agents occur and some cases involving full co-elutions will be presented and discussed to highlight the GC $\times$ GC improved resolution when compared to data from GC/MS.

The co-elution observed in the one-dimensional approach and the resolving power of the $\mathrm{GC} \times \mathrm{GC}$ can be observed in the Figure 2 , where the main targets used in the detection of norethandrolone and clostebol abuse ( $17 \alpha$-ethyl-5 $\beta$-estrane- $3 \alpha, 17 \beta$-diol and 4-chloroandrost-4-en-3 $\alpha$-ol-17-one, both respectively as TMS ethers) clearly co-elute in $2 \mathrm{a}$.

Norethandrolone ((17ß)-17-ethyl-17-hydroxyester-4-en-3-one, brand name Nivelar) is an anabolic steroid structurally similar with methyltestosterone, but with an ethyl group in C17. It is orally administered and has less androgenic activity than testosterone but equal anabolic activity. It was firstly used as a growth promoting agent in poultry.

Clostebol (4-chlorotestosterone, brand name Megagrisevit-Mono) is a low strength anabolic compound, which exhibits minimal androgenic potency. ${ }^{40}$ This steroid has a high potential of accidental doping 

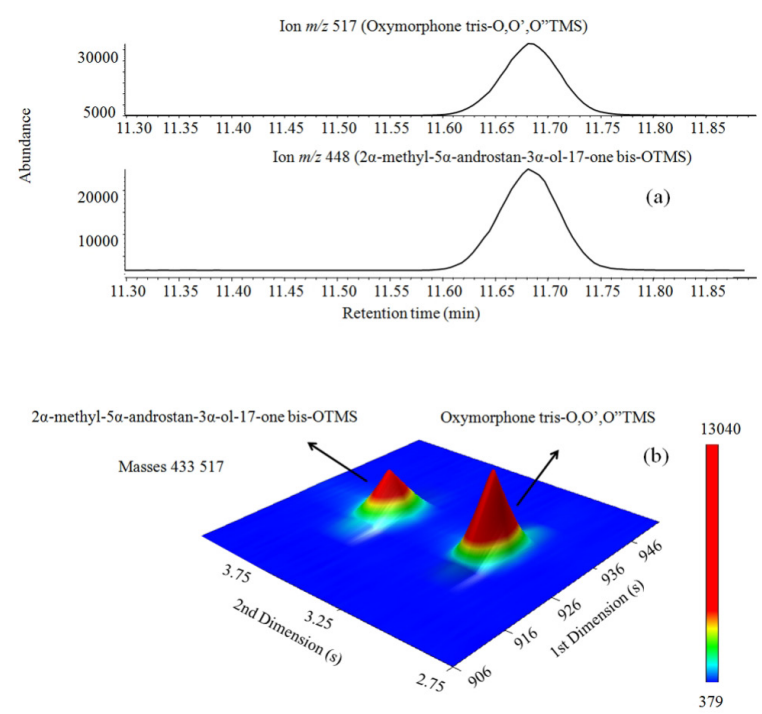

Figure 2. Results obtained between norethandrolone metabolite and clostebol metabolite as bis-OTMS ethers in one-dimensional $G C(a)$ and $G C \times G C(b)$

offence due to its availability in topical formulations. In Brazil, at least three adverse analytical findings were declared by our laboratory for clostebol with declaration of "accidental" topical clostebol use by athletes. ${ }^{41}$

After the GC $\times$ GC approach (Figure $2 b$ ), the analytes are completely resolved. The full spectra could be obtained for both analytes, without any interference, as demonstrated in Figure $2 \mathrm{~S}$ (supplementary material). No spectral deconvolution or software manipulation was necessary.

The potential concerning the improvement in specificity can be demonstrated to other classes of doping control agents. Figure 3 present the data obtained for a sample containing the target metabolite of drostanolone ( $2 \alpha-$ methyl-5 $\alpha$-androstane-3 $\alpha$-ol-17-one), and oximorphone, both as TMS ethers.
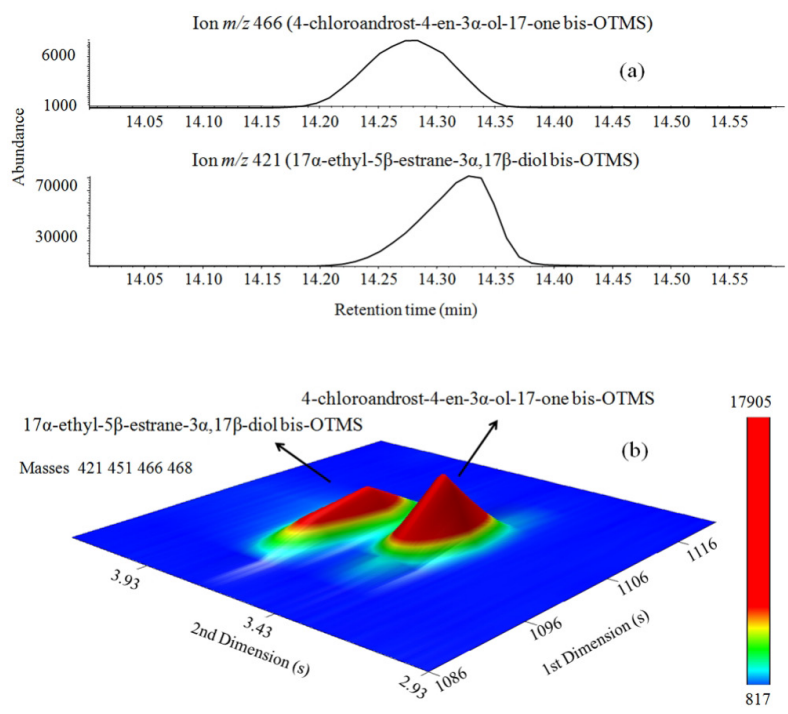

Figure 3. Results obtained for drostanolone metabolite as bis-OTMS and oxymorphone tris-OTMS in one-dimensional $G C(a)$ and $G C \times G C(b)$

Drostanolone (17- $\beta$-hydroxy-2 $\alpha$-methyl-5 $\alpha$-androstan-3-one) is an anabolic steroid commercialized as a propionate (trade name Masteron). It is reputed as highly androgenic and mildly anabolic, incapable of aromatization and with similar properties to dihydrotestosterone. It has been used to treat breast cancer since the 70's.

Oxymorphone (4,5 $\alpha$-epoxy-3,14-dihydroxy-17-methylmorphinan-6-one hydrochloride - brand name Opana ER) is a morphine-like opioid agonist, a narcotic agent classified in the Schedule II controlled substance and prohibited by WADA. The oral formulation of oxymorphone is indicated for the management of moderate to severe pain.

Again, without any interference, the full spectra could be obtained in both cases, as demonstrated in Figure $3 \mathrm{~S}$ (supplementary material). The achieved resolution and the full spectra acquisition have direct impact in analytical specificity.

The complexity of the sample regarding the matrix effect (selectivity) can be illustrated in the case involving the main urinary metabolite of $\Delta^{9}$-tetrahydrocannabinol (THC, marijuana active component). Cannabis is a permanent concern for public authorities of security, health and doping control as well. The main metabolite of THC in humans (11-nor-9-carboxy-THC, THCCOOH) is used as target analyte in doping scope. In the GC/MS conditions, it is possible to verify a high background, with high co-elution with endogenous compounds. Indeed, some of the most important fragments in the spectrum (including the base peak $\mathrm{m} / \mathrm{z}$ 505) are formed from endogenous interference, possibly a steroid present in every single urine sample in high concentration (Figure 4a). The analysis of THC main metabolite after sylilation shows the diagnostic fragments $\mathrm{m} / z$ 473, $\mathrm{m} / \mathrm{z}, 371$ and $\mathrm{m} / \mathrm{z}$ 488. These ions can be hardly identified in the full spectrum from GC/MS (quadrupole analyzer). Hence, the identification/quantification of $\mathrm{THCCOOH}$ relays on the selected ion monitoring acquisition.
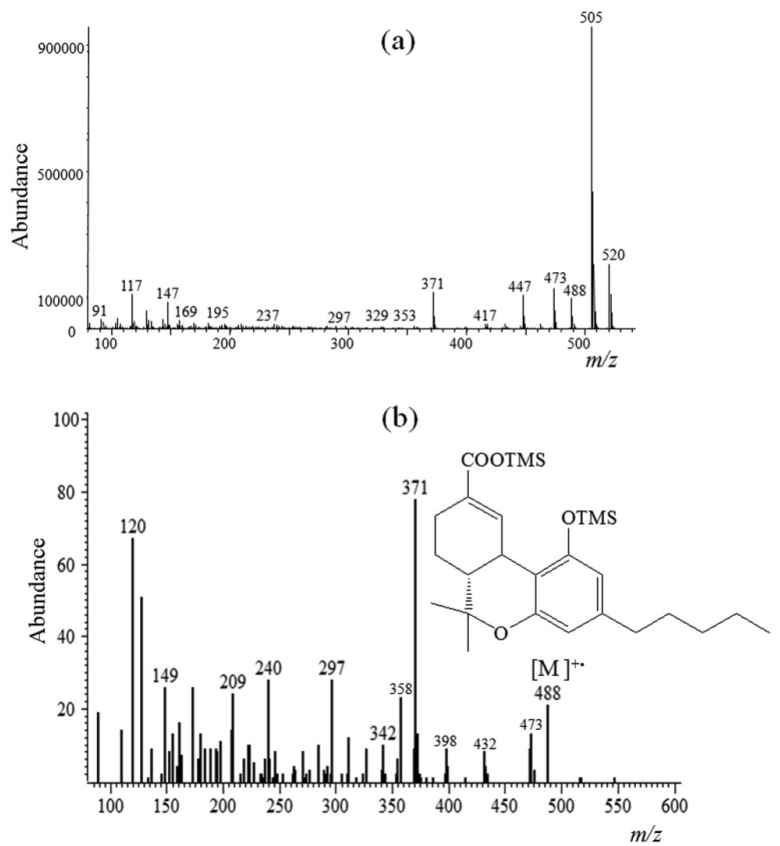

Figure 4. Selected region of mass spectra of the $\Delta-9-T H C$-11-oic acid bis-OTMS (molecular ion at m/z 448) in GC/MS (a) and in GC $\times G C$-TOFMS (b)

The spectrum of the THCCOOH obtained in the $\mathrm{GC} \times \mathrm{GC}$ system is presented in Figure 4b. Despite of the improvement of the chromatographic resolution, it was possible to verify an important contribution of the background (data not shown). It is a demonstration of how complex and challenging an urine sample can be for toxicological analysis. Nevertheless, the spectral deconvolution operations available in TOFMS apparatus allow the achievement of a not contaminated spectrum (Figure 4b). 
The examples above show the increase in resolution obtained with the $\mathrm{GC} \times \mathrm{GC}$ system. This improvement has direct impact in the specificity and selectivity of the method. As a result, largely embracing sample preparations with poor specificity for a determinate analyte can be employed without prejudice for detectability. The high acquisition velocity provided by TOFMS analyzers enables the monitoring of hundreds of substances, which makes the GC $\times$ GC-TOFMS a very promising tool in doping control and toxicological analysis.

\section{CONCLUSIONS}

Forty doping agents from eight different pharmacological classes were correctly identified in spiked urine samples. The co-elution between exogenous compounds commonly observed in typical 1D$\mathrm{GC}$ analyses are completely resolved in $\mathrm{GC} \times \mathrm{GC}$. These results demonstrate the huge improvement in specificity observed in the comprehensive chromatography system. The TOFMS analyzer allow full spectra acquisition and spectral deconvolution without matrix interference as a result from the improvement of chromatographic resolution. With these results, it is possible to foresee the implementation of an ultimate comprehensive monitoring approach in a single injection for hundreds of doping agents making the full mass spectra available.

\section{SUPPLEMENTARY MATERIAL}

Figures $1 \mathrm{~S}$ to $3 \mathrm{~S}$ are available at http://quimicanova.sbq.org.br, in PDF file, with free access.

\section{ACKNOWLEDGMENTS}

Brazilian Ministry of Sport, CNPq, FUJB, CBF, FAPERJ for funding and Leco for technical support. CAPES for scholarship to $\mathrm{S}$. S. Barbosa, techinicians for sample preparation, Dr. R. Pereira (IQ/ UFRJ) for support on figures.

\section{REFERENCES}

1. Pereira, H. M. G.; Padilha, M. C.; Bento, R. M. A.; Cunha, T. P.; Lascas, N. A. G.; Aquino Neto, F. R.; Trends Anal. Chem. 2008, 27, 648.

2. Tsivou, M.; Kioukia-Fougia, N.; Lyris, E.; Aggelis, Y.; Fragkaki, A.; Kiousi, X.; Simitsek, Ph.; Dimopoulou, H.; Leontiou, I. P.; Stamou, M.; Spyridaki, M.; Georgakopoulos, C. G.; Anal. Chim. Acta 2006, 555, 1.

3. Huestis, M. A.; Smith, M. L.; Drug Discov. Today: Technol. 2006, 3, 49.

4. Shackleton, C.; Steroids 2009, 74, 288.

5. Bowers, L. D.; Clark, R.V.; Shackleton, C. H. L.; Steroids 2009, 74, 285.

6. Donike, M.; Drug Test Anal. 2011, 3, 15.

7. Huenerbein, A.; Marques, M. A. S.; Pereira, A. S.; Aquino Neto, F. R.; J. Chromatogr., A 2003, 985, 375.

8. Marques, M. A.S.; Pereira, H. M. G.; Aquino Neto, F. R.; J. Braz. Chem. Soc. 2006, 17, 382.

9. Marques, M. A. S.; Pereira, H. M. G.; Padilha, M. C.; Aquino Neto, F. R.; J. Chromatogr., A 2007, 1150, 215.

10. Schänzer, W.; Delahaut, P.; Geyer, H.; Machnik, M.; Horning, S.; J. Chromatogr., B: Anal. Technol. Biomed. Life Sci. 1996, 687, 93.

11. Opfermann, G.; Schänzer, W. Recent Advances in Doping Analysis (4); Donike, M.; Geyer, H.; Gotzmann, A.; Mareck-Engelke, U., eds.; Sport and Buch Straub: Köln, 1996, p. 247.

12. van Thuyne, W.; van Eenoo, P.; Delbeke, F. T.; J. Chromatogr., A 2008, 1210,193

13. http://www.wada-ama.org/World-Anti-Doping-Program/Sports-andAnti-Doping-Organizations/International/Standards/Testing/2012/ WADA_IST_2012_EN.pdf, accessed January 2012.
14. http://www.wada-ama.org/Documents/World_Anti-Doping_Program/ WADP-Prohibited-list/2012/WADA_Prohibited_List_2012_EN.pdf, accessed January 2012.

15. Weldegergis, B. T.; Crouch, A. M.; Górecki, T.; de Villiers, A.; Anal. Chim. Acta 2011, 701, 98.

16. Waldhier, M. C.; Almstetter, M. F.; Nürnberger, N.; Gruber, M. A.; Dettmer, K.; Oefner P. J.; J. Chromatogr., A 2011, 1218, 4537.

17. Gao, X.; Yang, X.; Mitrevski, B. S.; Marriott, P. J.; J. Sep. Sci. 2011, 34, 1157.

18. Johanningsmeier, S. D.; McFeeters, R. F.; J. Food Sci. 2011, 76, 168.

19. De Vos, J.; Gorst-Allman, P.; Rohwer, E.; J. Chromatogr., A 2011, 1218, 3282.

20. Avila, B. M.; Pereira, R.; Gomes, A. O.; Azevedo, D. A.; J. Chromatogr., A 2011, 1218, 3208.

21. Silva, J. M.; Zini, C. A.; Caramão, E. B.; J. Chromatogr., A 2011, 1218, 3166.

22. Silva, R. S. F.; Aguiar, H. G. M.; Rangel, M. D.; Azevedo, D. A.; Aquino Neto, F. R.; Fuel 2011, 90, 2694.

23. Freitas, L. S.; von Mühlen, C.; Bortoluzzi, J. H.; Zini, C. A.; Fortuny, M.; Dariva C.; Coutinho, R. C. C.; Santos, A. F.; Caramão, E. B.; J. Chromatogr., A 2009, 1216, 2860.

24. Silva Jr, A. I.; Pereira, H. M. G.; Casilli, A.; Conceição, F. C.; Aquino Neto, F. R.; J. Chromatogr., A 2009, 1216, 2913.

25. Silva Jr, A. I.; Pereira, H. M. G.; Casilli, A.; Aquino Neto, F. R. In Recent Advances in Doping Analysis (15); Donike, M.; Geyer, H.; Gotzmann, A.; Mareck-Engelke, U., eds.; Sport and Buch Straub: Köln, 2007, p. 217.

26. http://www.wada-ama.org/Documents/World_Anti-Doping_Program/ WADP-IS-Laboratories/WADA_TD2010MRPLv1.0_Minimum\%20 Required\%20Performance\%20Levels_Sept\%2001\%202010_EN.pdf, accessed January 2012.

27. Mitrevski, B. S.; Brenna, J. T.; Zhang, Y.; Marriott, P. J.; J. Chromatogr., A 2008, 1214, 134.

28. Mitrevski, B. S.; Wilairat, P.; Marriott, P. J.; J. Chromatogr., A 2010, 1217, 127.

29. Mitrevski, B. S.; Wilairat, P.; Marriott, P.; J. Anal. Bioanal. Chem. 2010, 396,2503

30. Adahchour, M.; Beens, J.; Vreuls, R. J. J.; Brinkman, U. A. Th.; Trends Anal. Chem. 2006, 25, 540.

31. Pedroso, M. P.; Godoy, L. A. F.; Fidélis, C. H. V.; Ferreira, E. C.; Poppi, R. J.; Augusto. F.; Quim. Nova 2009, 32, 421.

32. Thevis, M.; Guddat, S.; Schänzer, W.; Steroids 2009, 74, 315.

33. Sekera, M. H.; Ahrens, B. D.; Chang, Y. C.; Starcevic, B.; Georgakopoulos, C.; Catlin, D. H.; Rapid Commun. Mass Spectrom. 2005, 19, 781.

34. Pereira, H. M. G.; Padilha, M. C.; Aquino Neto, F. R.; Bioanalysis 2009, 1,1475 .

35. ABNT; NBR ISO/IEC 17025:2005, General requirements for the competence of testing and calibration laboratories, ABNT, 2005.

36. Geyer, H.; Schänzer, W.; Mareck-Engelke, U.; Nolteersnsting, E.; Opfermann, G. In Recent Advances in Doping Analysis (5); Schänzer, W.; Geyer, H.; Gotzmann, A.; Mareck-Engelke, U. eds.; Sport \& Buch Strau, Köln, 1997, p. 99.

37. http://www.wada-ama.org/Documents/World_Anti-Doping_Program/ WADP-IS-Laboratories/WADA_TD2010IDCRv1.0_Identification\%20 Criteria\%20for\%20Qualitative\%20Assays_May\%2008\%202010_EN. doc.pdf, accessed January 2012.

38. Sardela, V. F.; Motta, M. T. R.; Padilha, M. C.; Pereira, H. M. G.; Aquino Neto, F. R.; J. Chromatogr., B: Anal. Technol. Biomed. Life Sci. 2009, 877, 3003 .

39. Adahchour, M.; Beens, J.; Vreuls, R. J. J.; Brinkman, U. A. Th.; Trends Anal. Chem. 2006, 25, 438.

40. Schänzer, W.; Donike, M.; Anal. Chim. Acta 1993, 275, 23.

41. Pereira, H. M.; Marques, M. A.; Talhas, I. B.; Aquino Neto, F. R.; Clin. Chem. 2004, 50, 456. 